Electronic Supporting Information for

An Environmentally Friendly Procedure for the Aqueous Oxidation of Benzyl Alcohols to Aldehydes with Dibromodimethylhydantoin (DBDMH) and Cyclodextrin - Scope and Mechanistic Insights

\author{
Sauradip Chaudhuri, Hossam Zaki and Mindy Levine*
}

*Department of Chemistry, University of Rhode Island, 51 Lower College Road, Kingston, RI 02881;

mlevine@chm.uri.edu; 401-874-4243 


\section{TABLE OF CONTETNS}

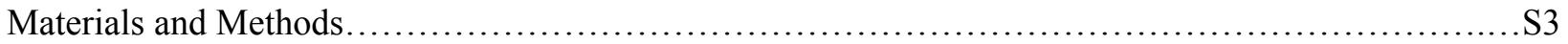

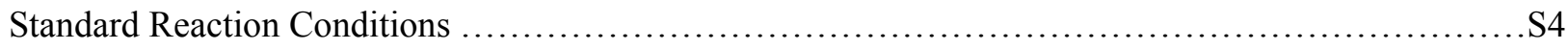

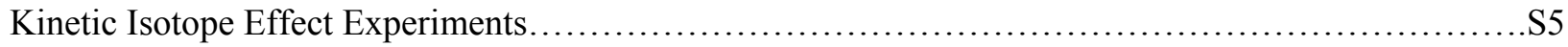

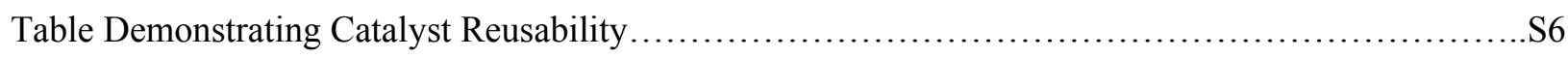

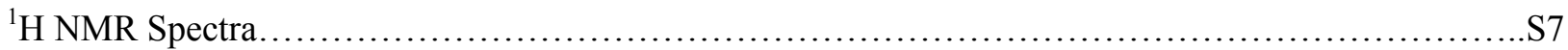




\section{Materials and Methods}

Proton NMR spectra were recorded using a Bruker $300 \mathrm{MHz}$ instrument, with the singlet peak of HDO at $4.79 \mathrm{ppm}$ as reference. All reagents, substrates, and solvents were obtained from Sigma Aldrich and used as received. Four different cyclodextrin solutions were screened: $\alpha$-cyclodextrin, $\beta$-cyclodextrin, methyl $\beta$-cyclodextrin and $\gamma$-cyclodextrin dissolved in deuterated water $\left(\mathrm{D}_{2} \mathrm{O}\right)$. A cyclodextrin-free $\mathrm{D}_{2} \mathrm{O}$ solution was used as the control. The same procedure was adopted for all the cyclodextrins and the control. 


\section{Standard Reaction Conditions}

To a clean and dry small vial, a solution of substrate $\mathbf{1}$ (15.0 $\mu \mathrm{mol}, 1.0$ equivalent) was made using an aqueous cyclodextrin solution $(1.0 \mathrm{~mL})$ in $\mathrm{D}_{2} \mathrm{O}$. DBDMH $3(4.3 \mathrm{mg}, 15.0 \mu \mathrm{mol}, 1.0$ equivalent $)$ was added to the reaction mixture and sonicated to make sure that the reagents were well suspended. The reaction mixture was heated at $60{ }^{\circ} \mathrm{C}$ with occasional shaking to maintain the homogeneity of the solution. After the desired period of time, the ${ }^{1} \mathrm{H}$ NMR spectrum of the reaction mixture was recorded to determine the percent conversion.

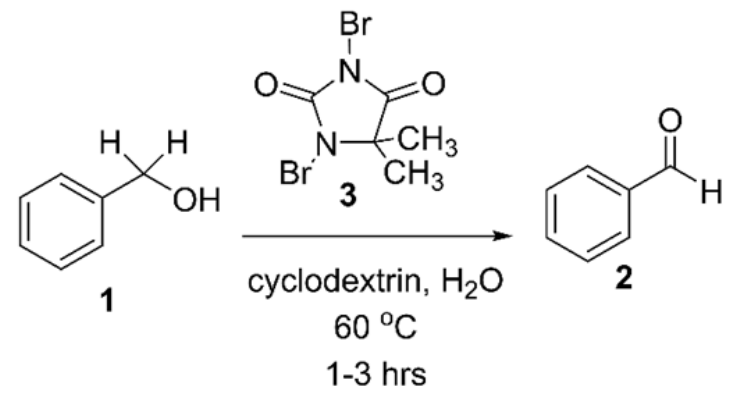

\section{NMR Analysis}

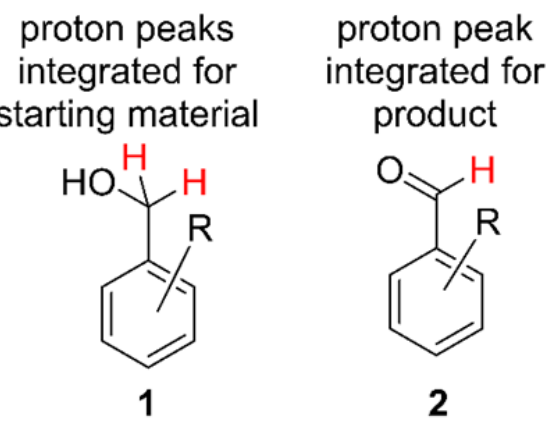

Figure 1. ${ }^{1} \mathrm{H}$ NMR peaks of protons (marked in red) integrated for the starting material $\mathbf{1}$ and product 2.

The percent conversion of each reaction was calculated based on the following equation:

$\%$ Conversion $=[($ Integration of the product peak $) /(($ Integration of the product peak $)+($ Integration of the starting material peak)/2)] x $100 \%$

The starting material NMR peak used in this equation corresponds to 2 benzyl protons of compound 1 and the product peak used for this equation corresponds to the 1 aldehyde proton of the product 2 (Figure 1). The integrations of the NMR peaks were the relative areas under the curve measured against a calibrated standard corresponding to the anomeric protons of the cyclodextrin hosts. 


\section{Kinetic Isotope Effect Experiments}

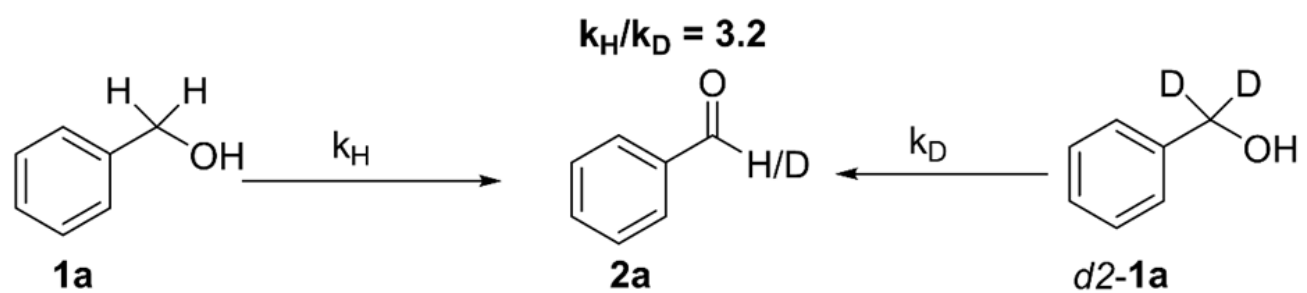

Two separate solutions of substrate 1a and $d 2-1 \mathbf{a}(15.0 \mu \mathrm{mol}, 1.0$ equivalent) were made using $5 \mathrm{mM}$ aqueous $\alpha$-cyclodextrin solution $\left(1.0 \mathrm{~mL}, 5.0 \mu \mathrm{mol}, 0.33\right.$ equivalents) in $\mathrm{D}_{2} \mathrm{O}$. DBDMH 3 (4.3 $\mathrm{mg}, 15.0$ $\mu \mathrm{mol}, 1.0$ equivalent) was added to the reaction mixtures and sonicated to make sure that the reagents were well suspended. The reaction mixtures were heated at $60{ }^{\circ} \mathrm{C}$ with occasional shaking to maintain the homogeneity of the solutions for 1 hour. ${ }^{1} \mathrm{H}$ NMR spectra of the reaction mixtures were recorded to determine the percent conversions.

Percent conversions of alcohol substrates 1 a and $d 2-1$ a to aldehyde $2 a$

\begin{tabular}{|c|c|c|c|c|}
\hline Substrate & Equivalents of substrate & Equivalents of compound 3 & \% Conversion & \multirow{2}{*}{$\mathbf{k}_{\mathbf{H}} / \mathbf{k}_{\mathbf{D}}$} \\
\hline 1a & $15 \mu \mathrm{mol}$ & $15 \mu \mathrm{mol}$ & 26 & \multirow{2}{*}{3.2} \\
\hline$d 2-1 a$ & $15 \mu \mathrm{mol}$ & $15 \mu \mathrm{mol}$ & 8 & \\
\hline
\end{tabular}

${ }^{a}$ Percent conversions were calculated based on the ${ }^{1} \mathrm{H}$ NMR analysis of the reaction mixture.

${ }^{\mathrm{b}}$ The reaction was run with $\alpha$-cyclodextrin ( 0.33 equivalents) for 0.5 hours at $60{ }^{\circ} \mathrm{C}$ 
Table Demonstrating Catalyst Reusability

\begin{tabular}{|c|c|c|c|c|c|}
\hline $\begin{array}{c}\text { Number of Re- } \\
\text { runs of } \\
\text { Catalyst }\end{array}$ & $\begin{array}{c}\text { Starting } \\
\text { Material 1a } \\
(\%)^{\mathrm{a}}\end{array}$ & $\begin{array}{c}\text { Br-benzyl } \\
\text { alcohol (\%) }\end{array}$ & $\begin{array}{c}\text { Br- } \\
\text { Aldehyde }(\%)^{\mathrm{a}}\end{array}$ & $\begin{array}{c}\text { Acid bromide } \\
(\%)^{\mathrm{a}}\end{array}$ \\
\hline 1st & 15 & - & - & 10 & 75 \\
\hline 2nd & - & - & - & 26 & 74 \\
\hline 3rd & - & - & 22 & 16 & 62 \\
\hline
\end{tabular}

${ }^{a}$ Percent conversions were calculated based on ${ }^{1} \mathrm{H}$ NMR analysis of the reaction mixture. 


\section{${ }^{1}$ H NMR SPECTRA}

\section{Benzyl alcohol 1a}
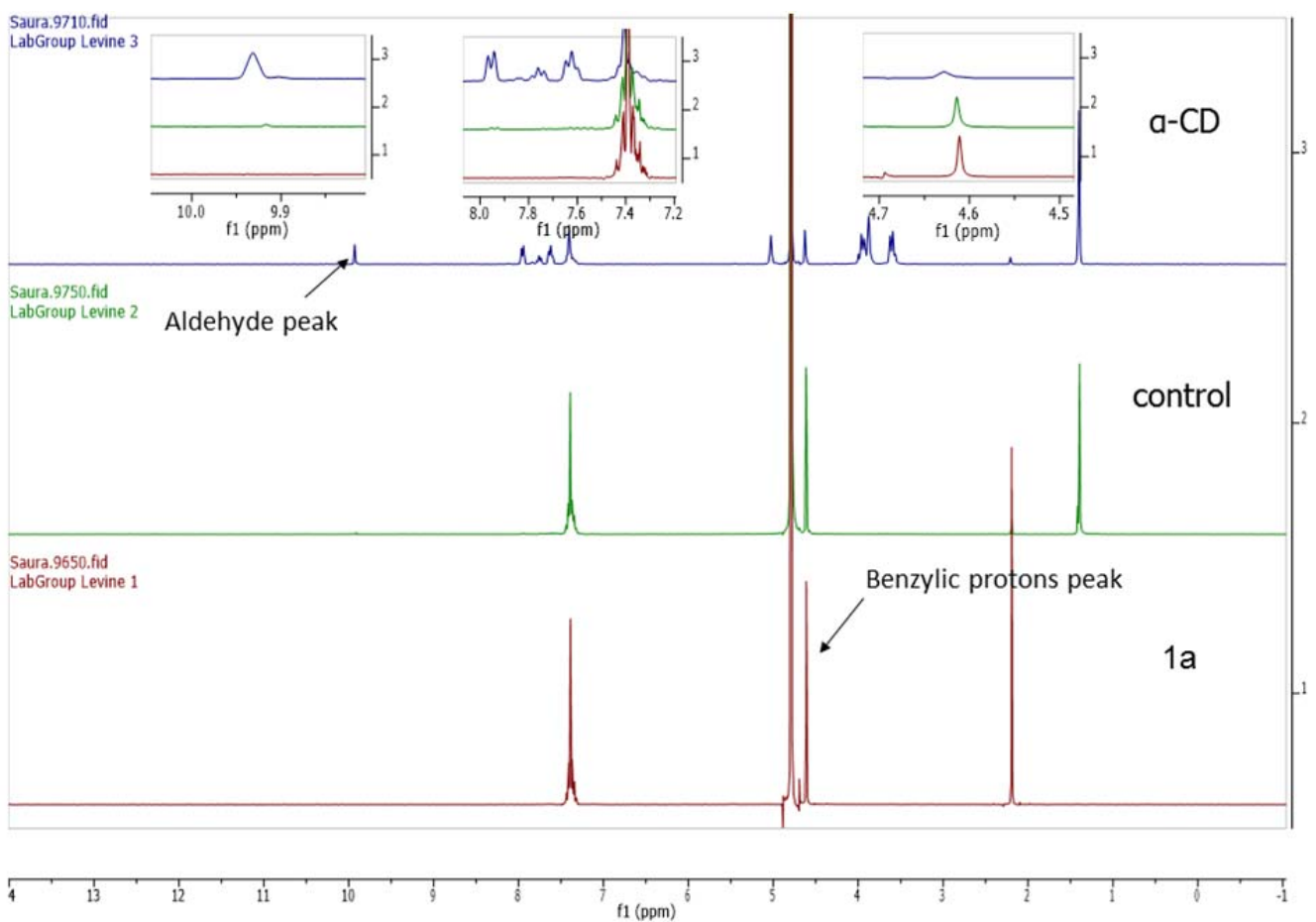

\section{4-methyl benzyl alcohol $1 b$}

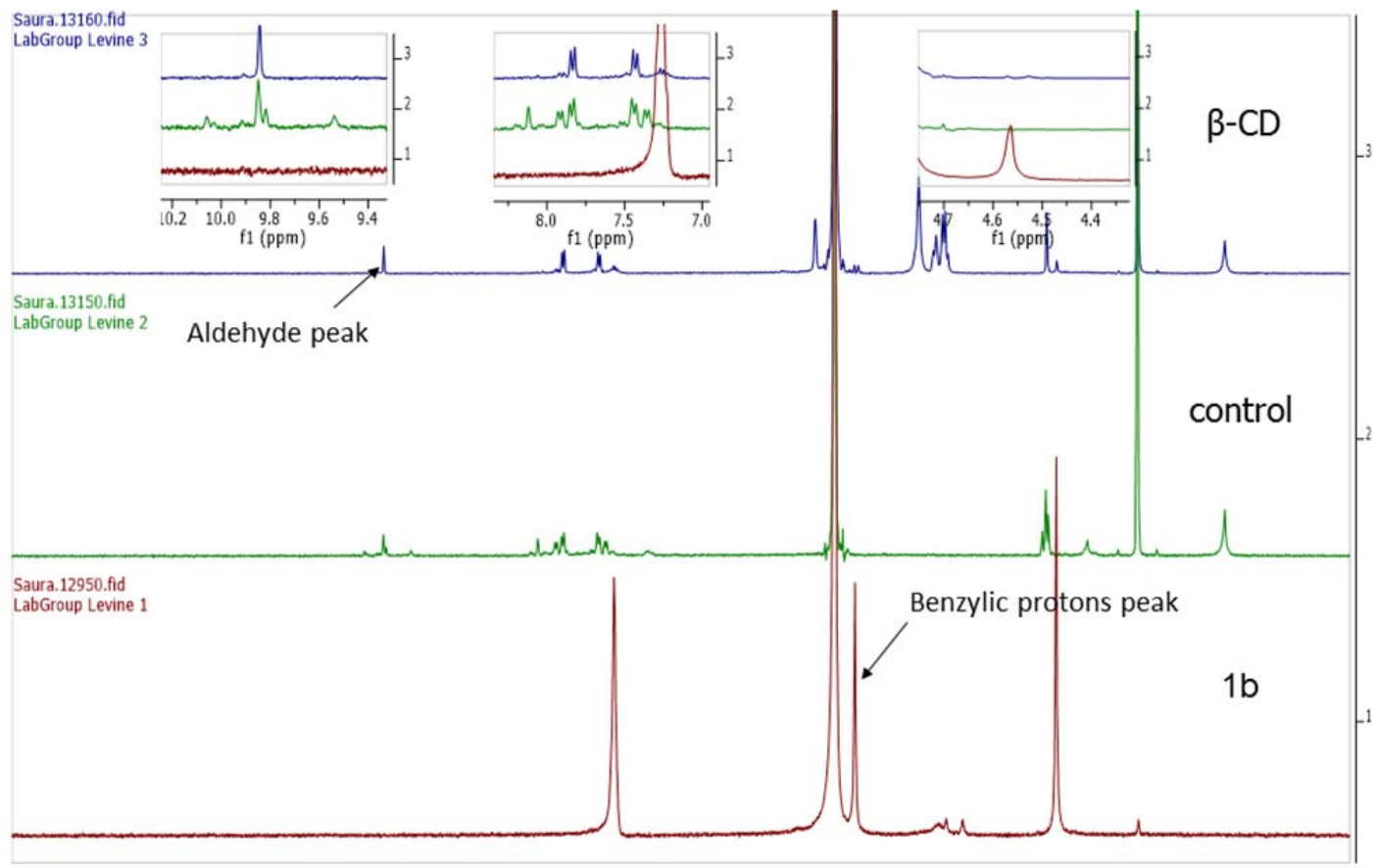

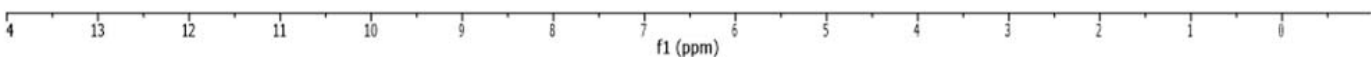




\section{3-methyl benzyl alcohol 1c}

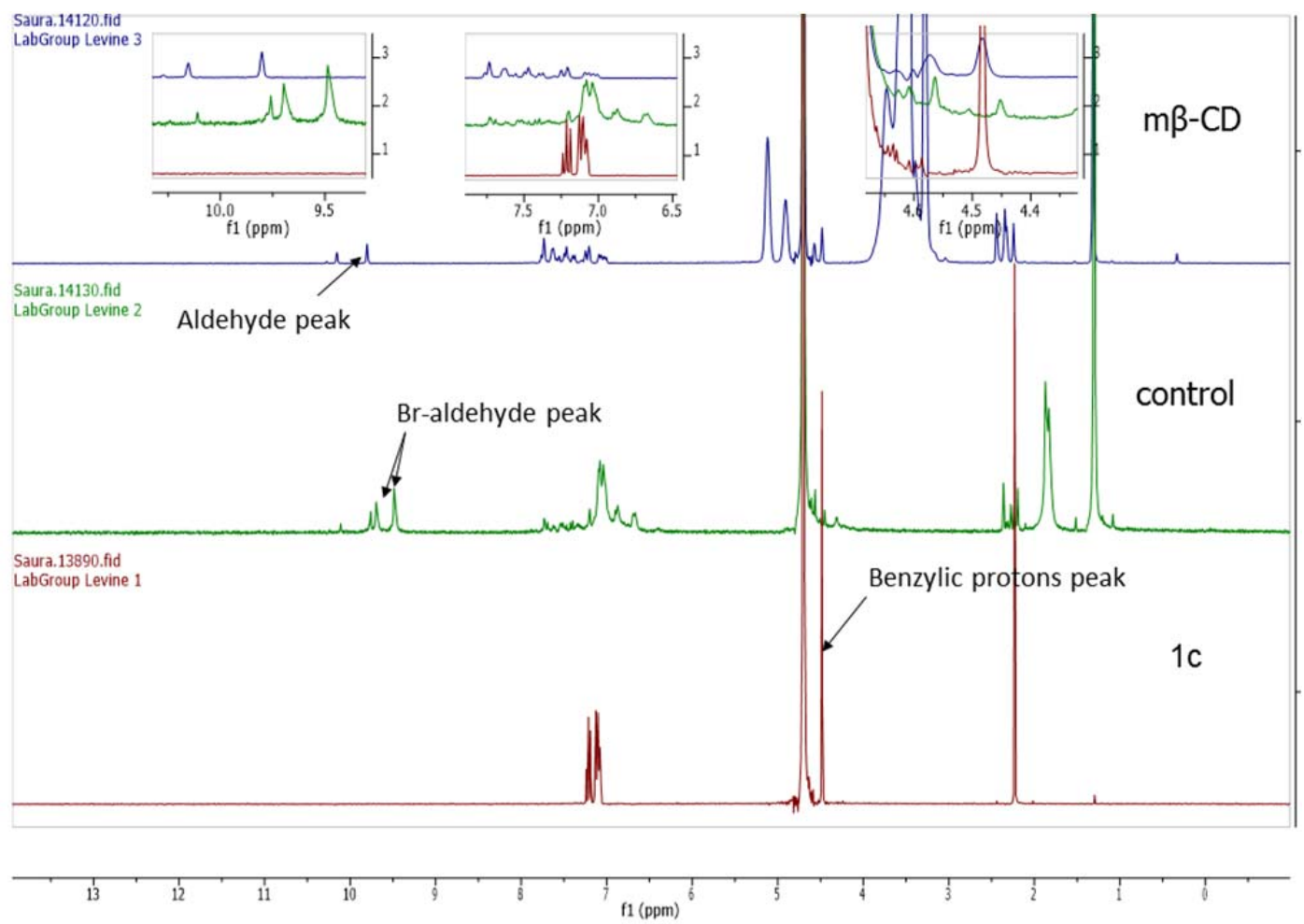

\section{4-chloro benzyl alcohol 1d}
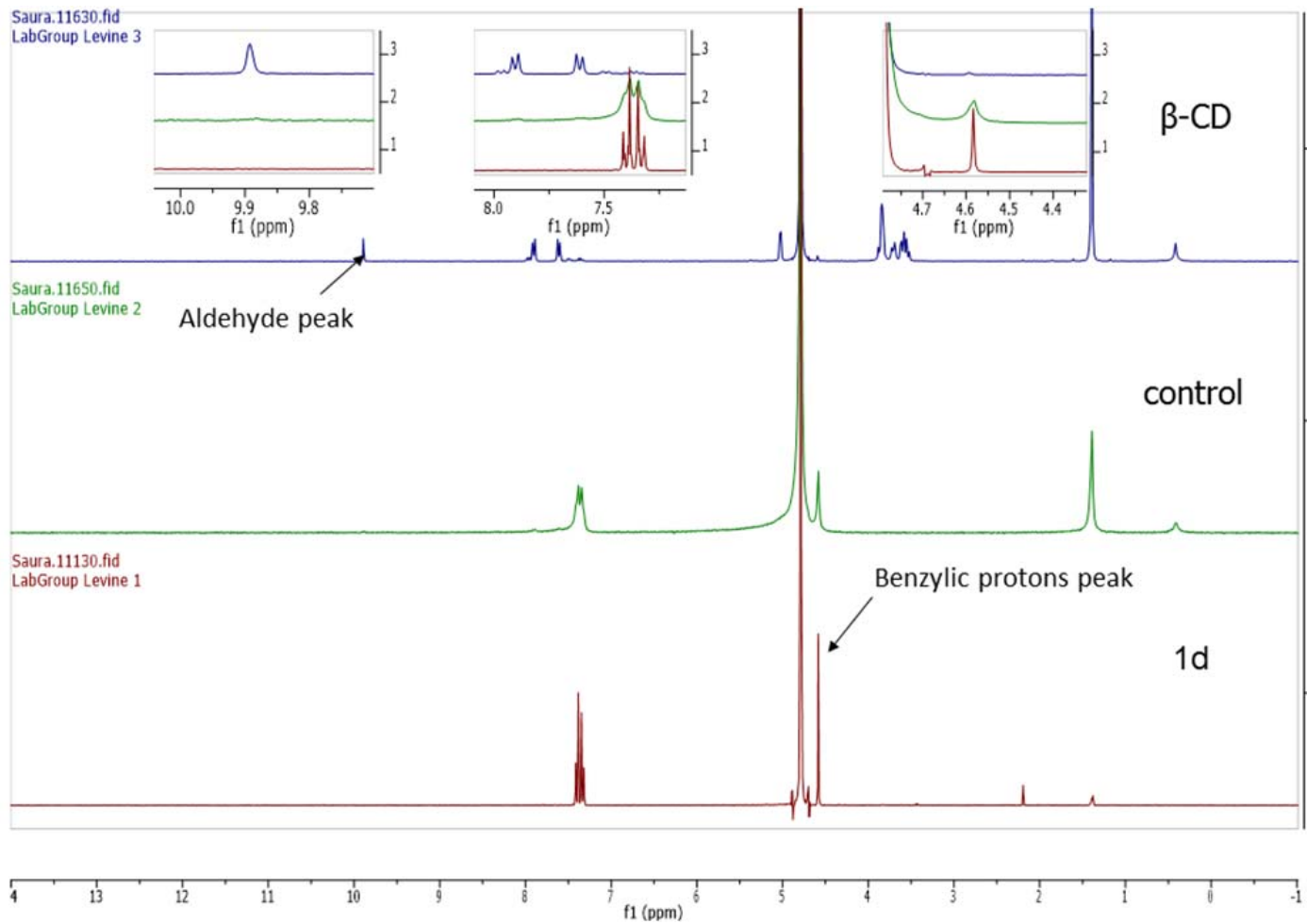


\section{4-trifluoromethyl benzyl alcohol 1e}
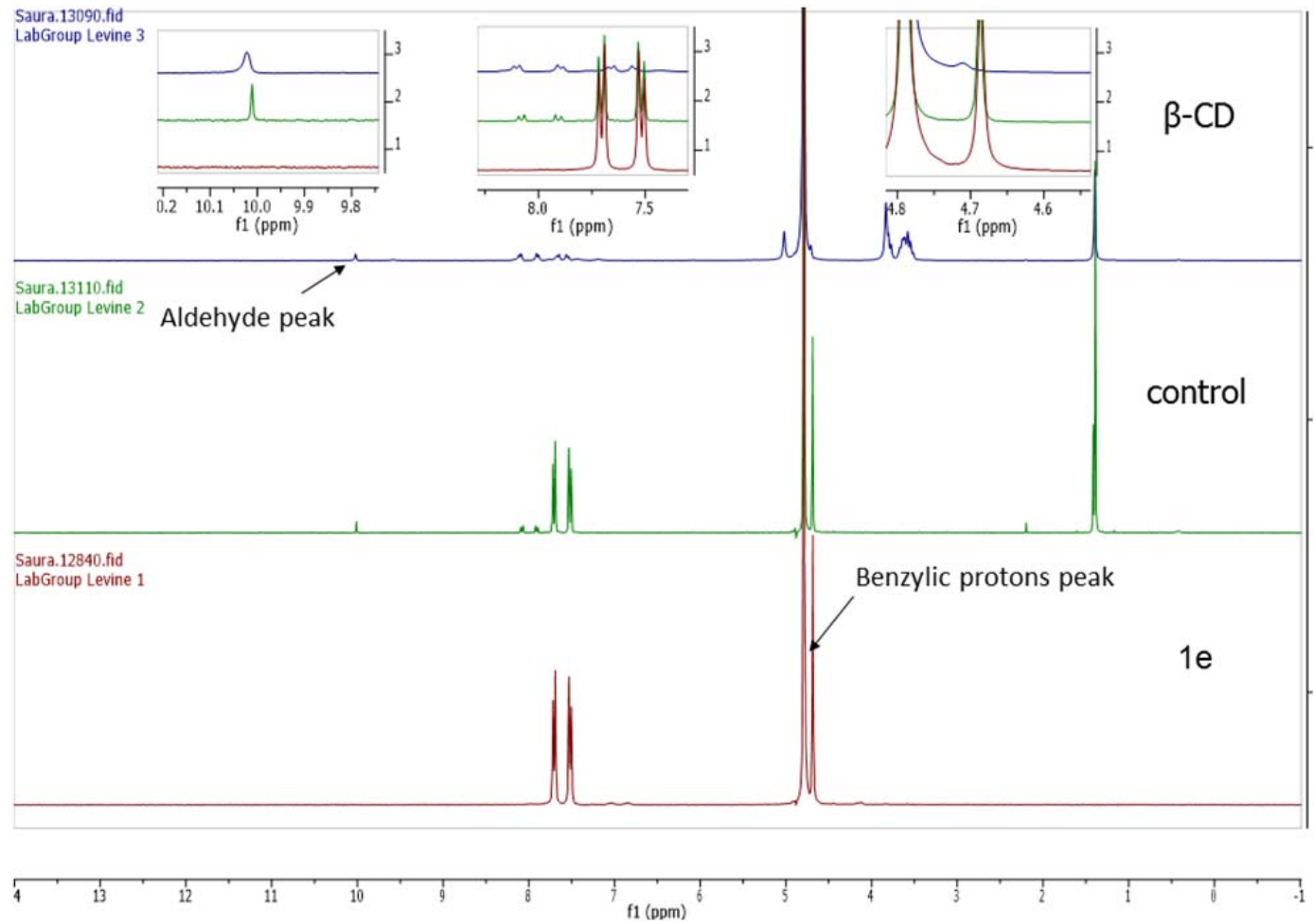

\section{3-bromo benzyl alcohol 1f}

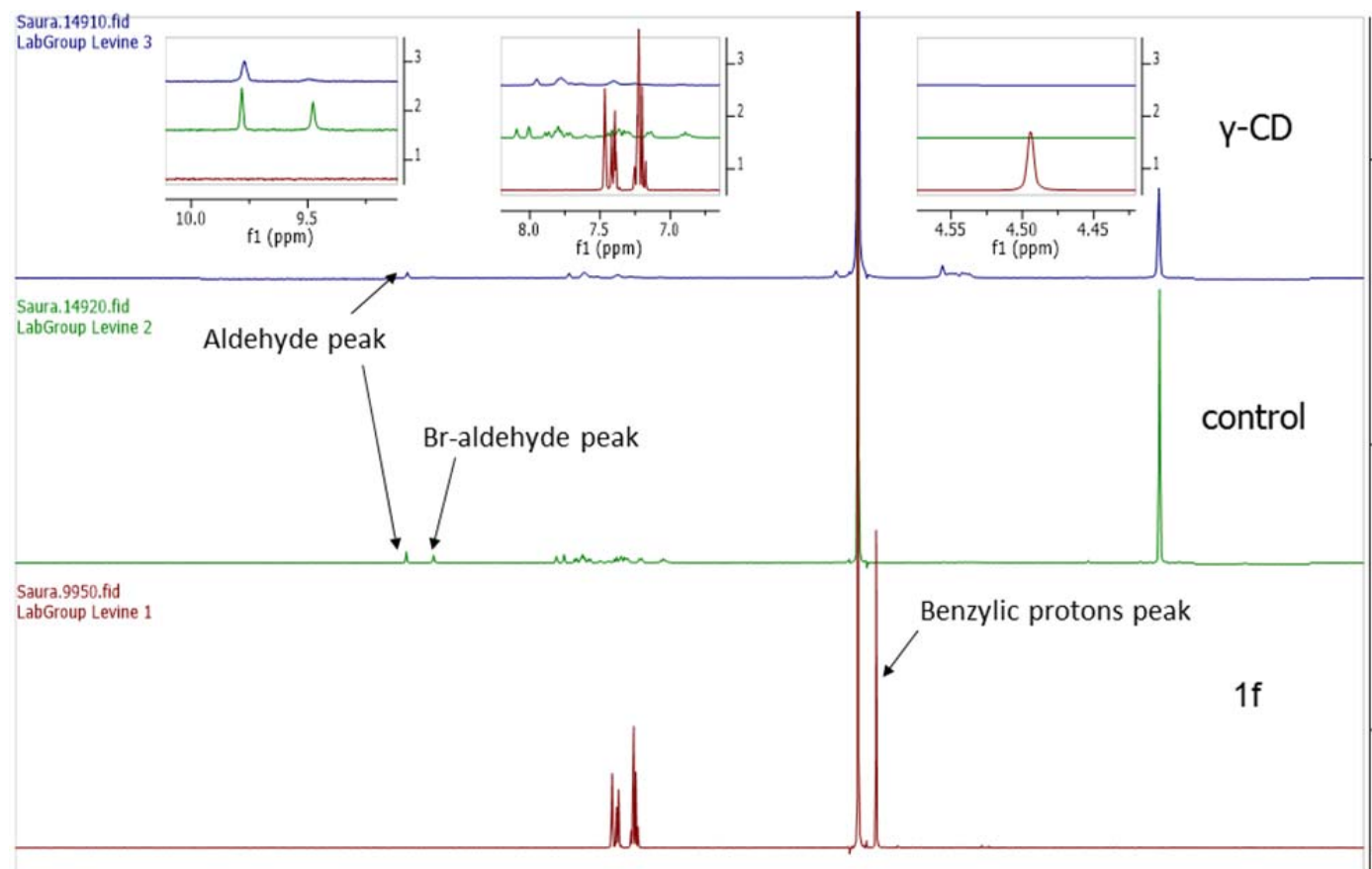

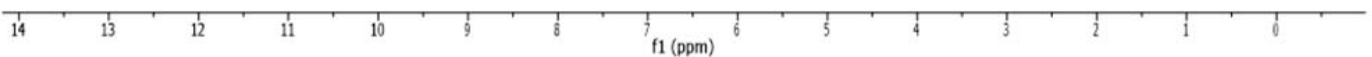




\section{4-bromo benzyl alcohol 1g}
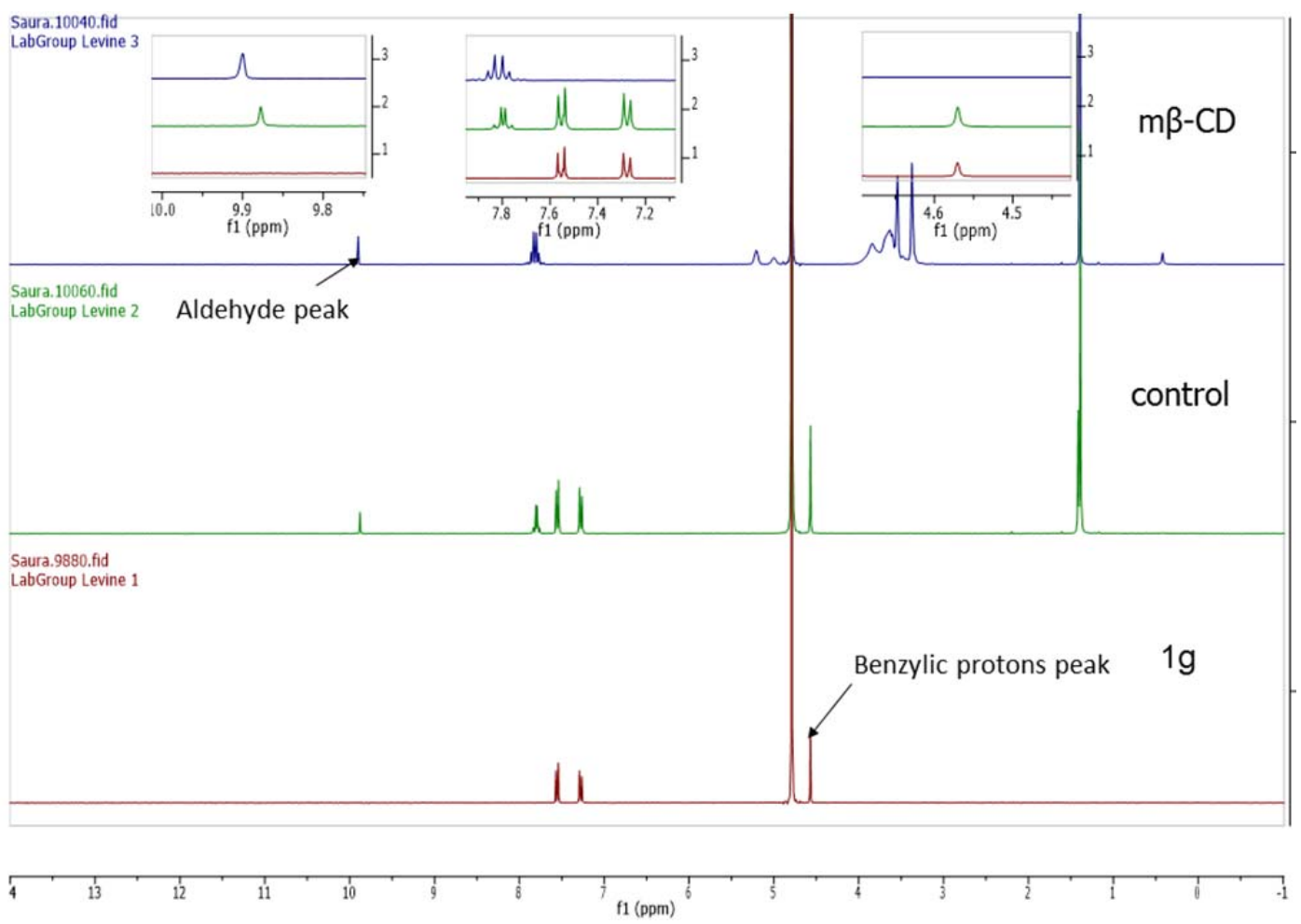

\section{4-nitro benzyl alcohol 1h}

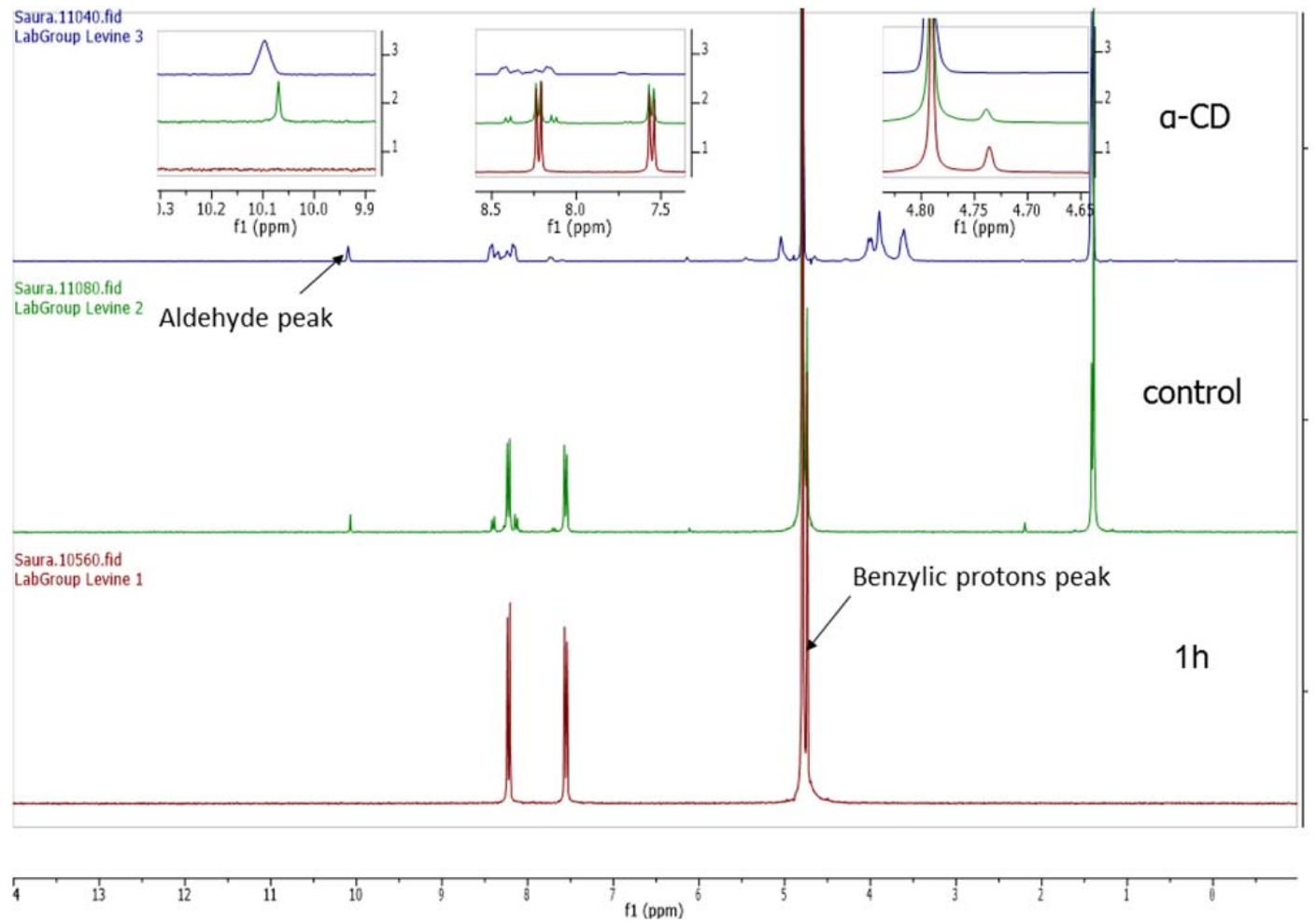




\section{2-nitro benzyl alcohol 1i}
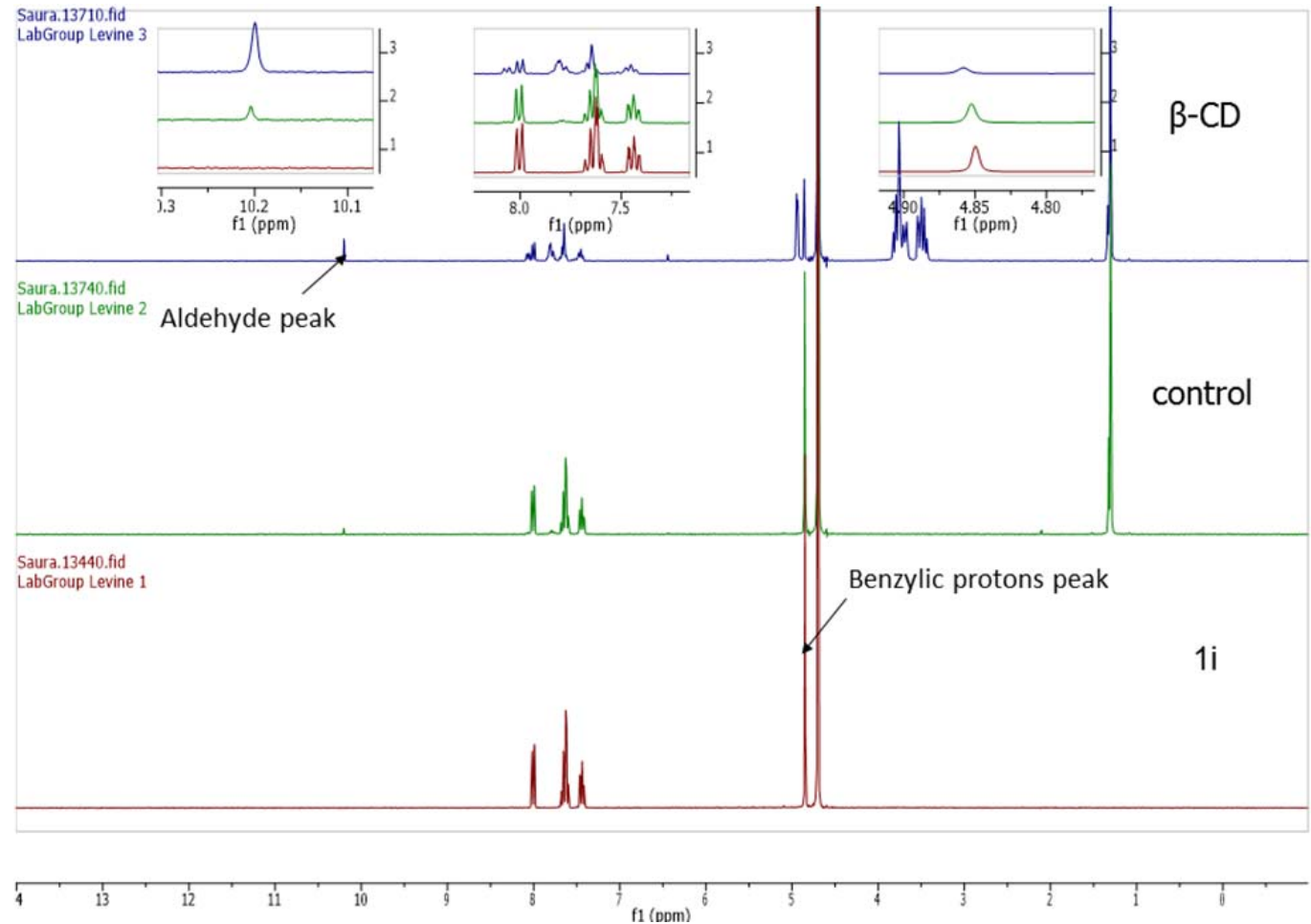

\section{4-iodo benzyl alcohol $\mathbf{1 j}$}
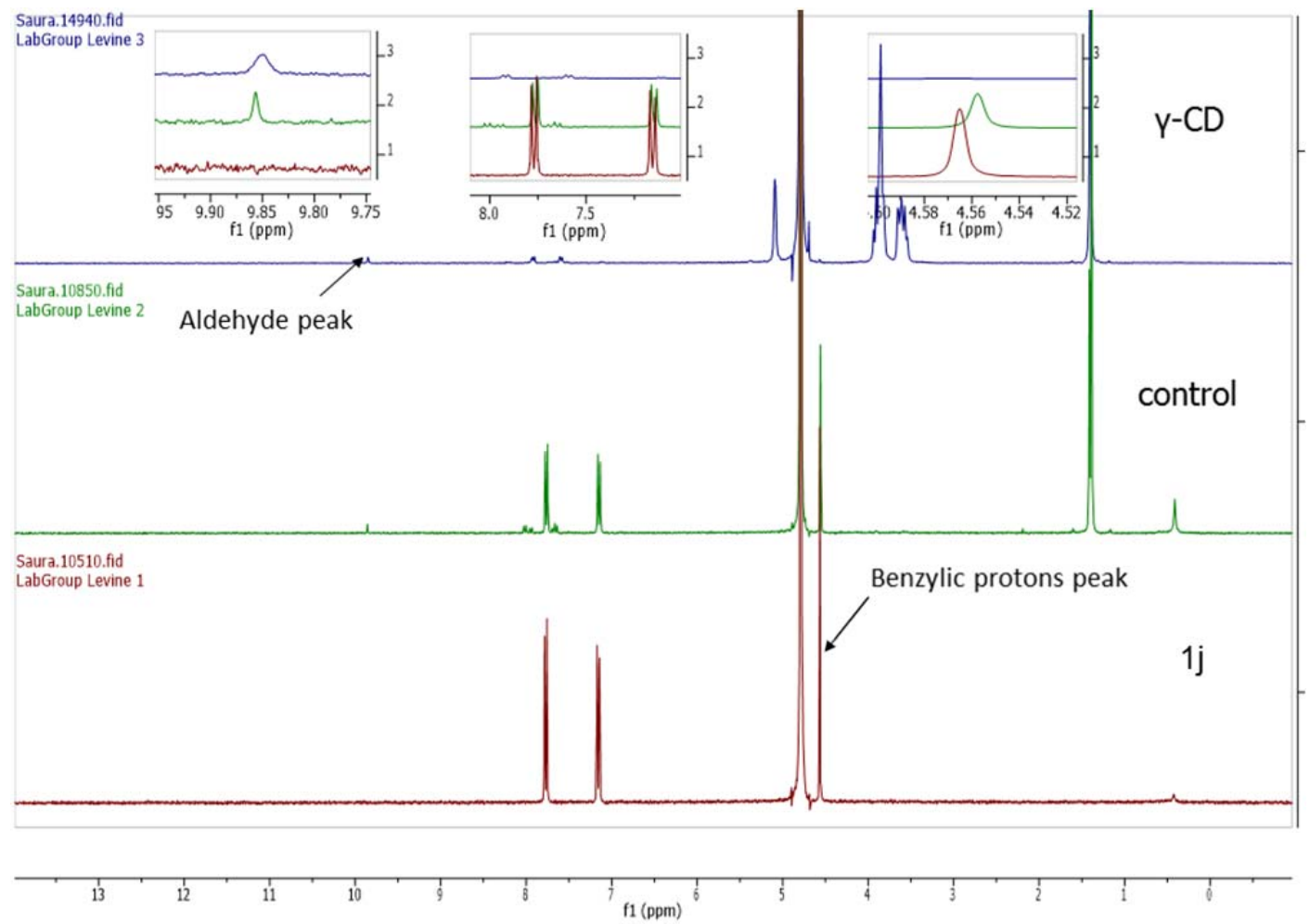
2-chloro-5-methylhydroxy pyridine $1 \mathrm{k}$
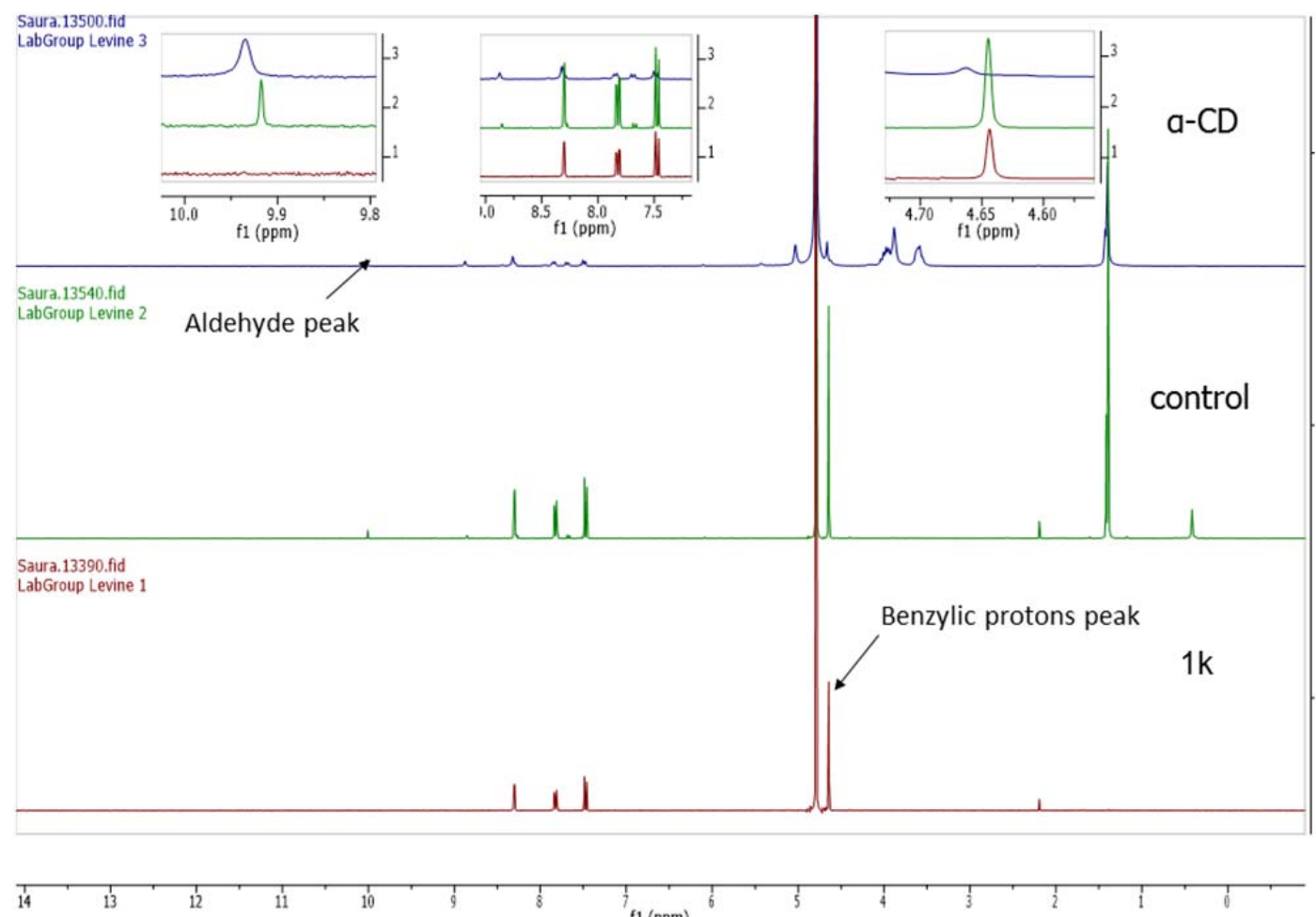

\section{2-chloro benzyl alcohol 11}

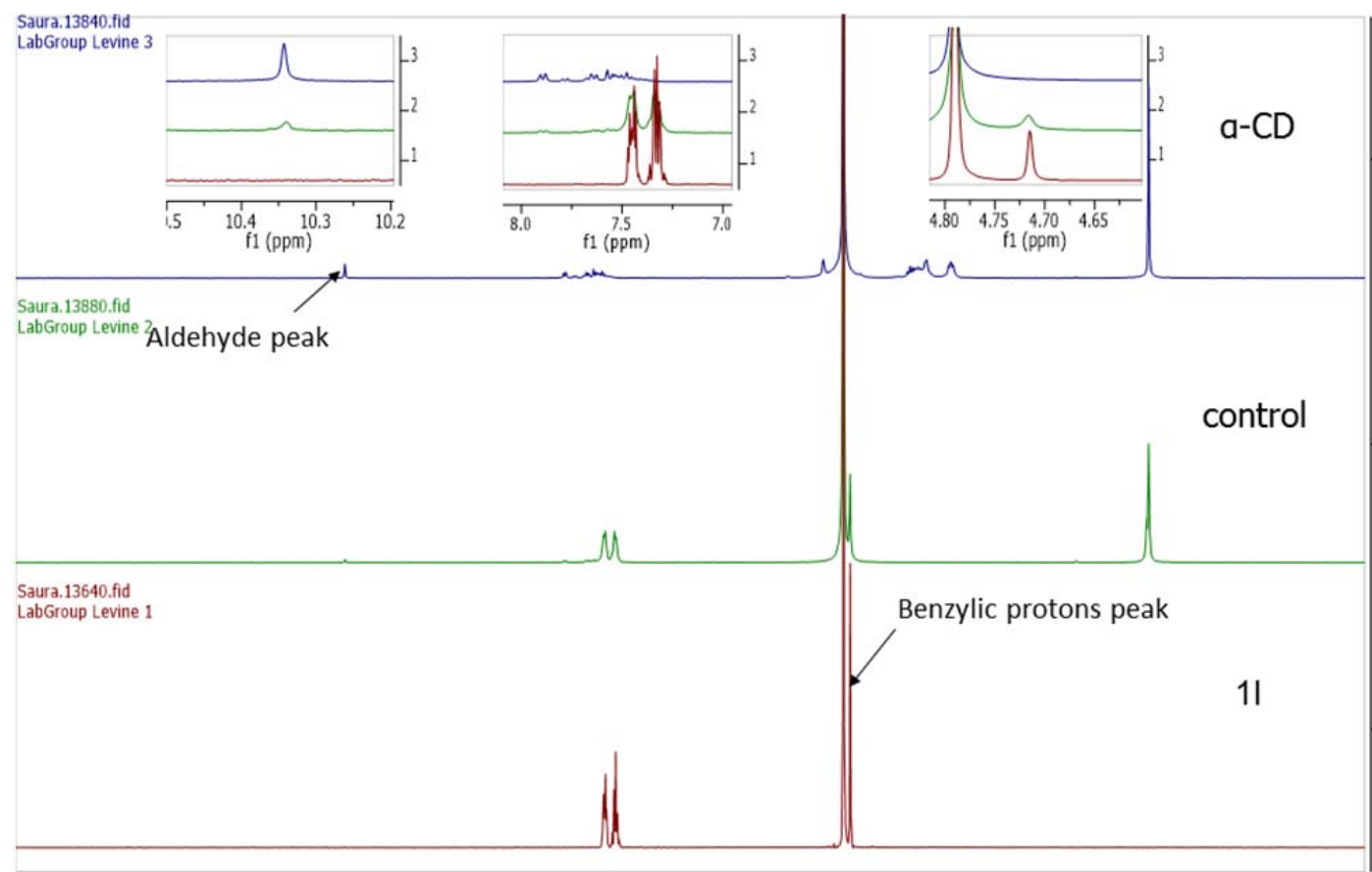

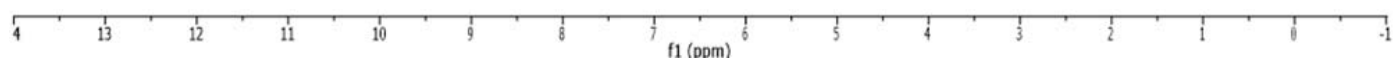




\section{4-methoxy benzyl alcohol 1m}
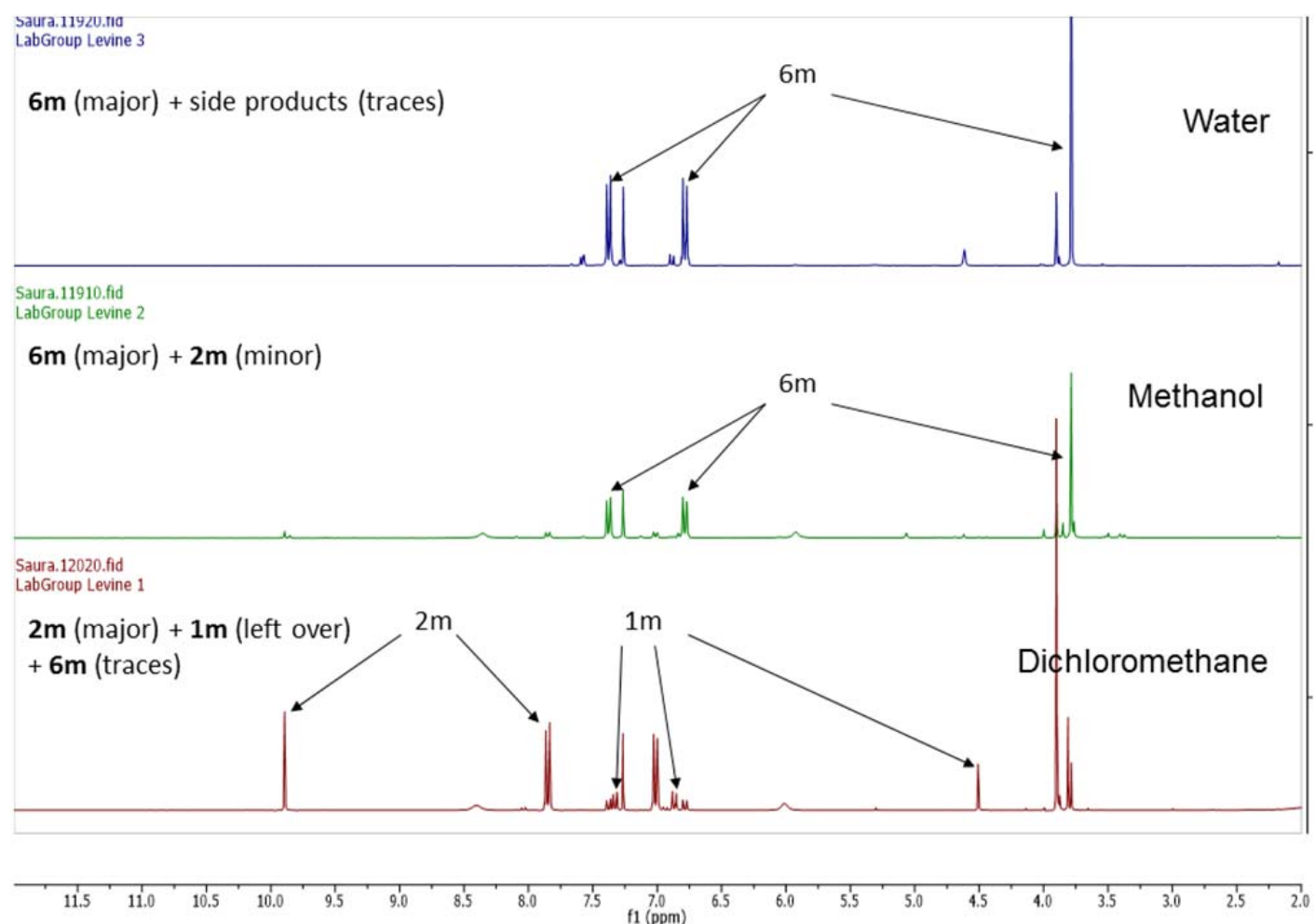


\section{${ }^{1}$ H NMR Spectra Demonstrating Catalyst Reusabillity}
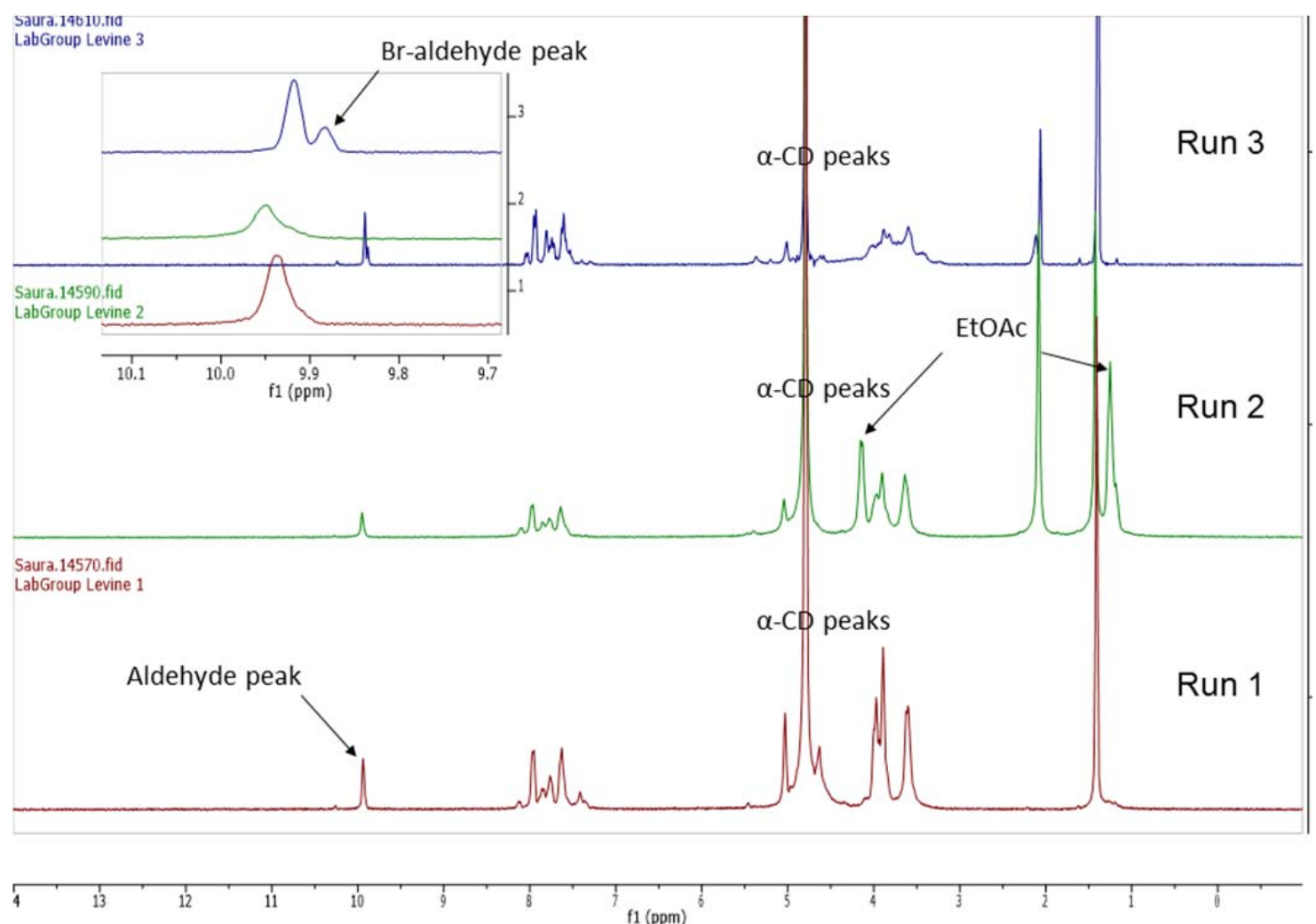

\section{${ }^{1}$ H NMR Spectra Demonstrating Reactivity of Reagent 3 in the Presence of Cyclodextrin}
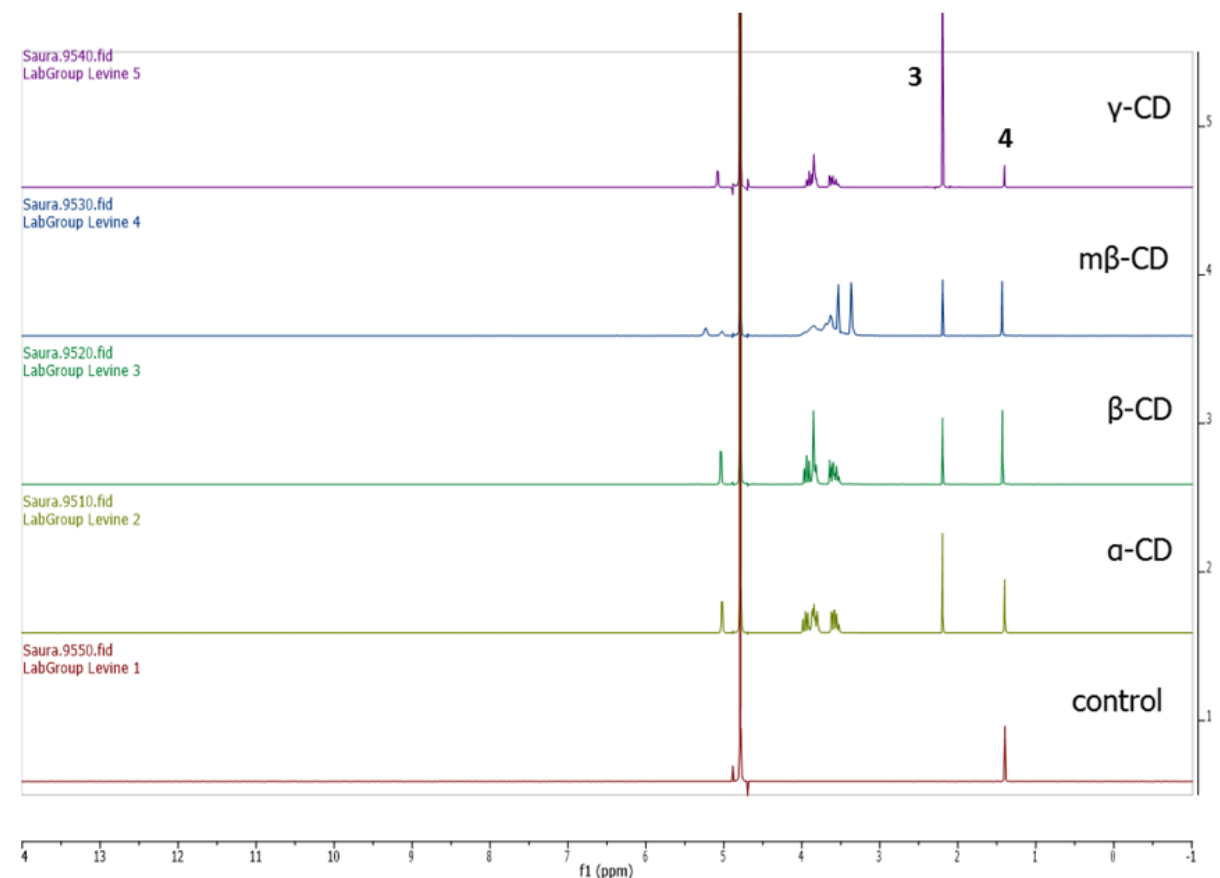
${ }^{1}$ H NMR Spectra Demonstrating Reactivity of Reagent 3 in the Presence of Cyclodextrin and One Equivalent of 1a

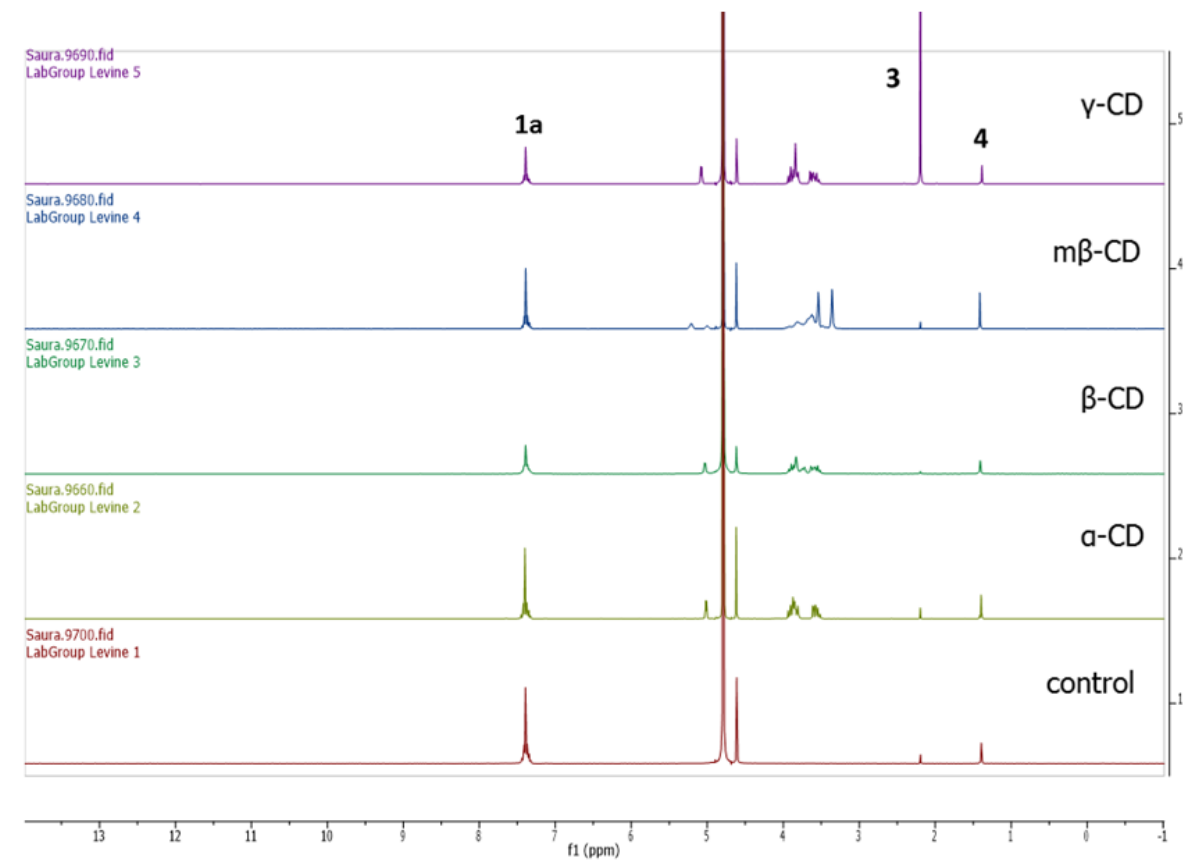

Table Illustrating the \%N-Br bond dissociation of reagent 3 in the Presence of Cyclodextrin and One Equivalent of 1a at standard reaction conditions (Calculated based on the NMR peak integrals of 3 and 4)

\begin{tabular}{|c|c|c|}
\hline CDs (0.33 eq.) & 3 (rt, 0 mins) & $3+1 a\left(60^{\circ} \mathrm{C}, 0.5 \mathrm{hrs}\right)$ \\
\hline$\alpha-C D$ & 50 & 58 \\
\hline$\beta-C D$ & 66 & 66 \\
\hline $\mathrm{m} \beta-\mathrm{CD}$ & 68 & 69 \\
\hline$\gamma-\mathrm{CD}$ & 11 & 14 \\
\hline control & 100 & 100 \\
\hline
\end{tabular}

